\title{
Developmental differences in young children's self-regulation
}

\author{
Antonia Zachariou and David Whitebread \\ University of Roehampton and University of Cambridge
}

\begin{abstract}
Author Note
Antonia Zachariou, School of Education, University of Roehampton, London, UK and Faculty of Education, University of Cambridge, Cambridge, UK

David Whitebread, Faculty of Education, University of Cambridge, UK

This study was partially funded by an A.G. Leventis Foundation grant awarded to Antonia Zachariou.

Correspondence concerning this article should be addressed to Antonia Zachariou, School of Education, University of Roehampton, Roehampton Lane, SW15 5PJ, London, UK. E-mail: antonia.zachariou@ roehampton.ac.uk. Phone number: +44 (0)20 83923712.
\end{abstract}

Ethical clearance for this project was given by the Faculty of Education, University of Cambridge.

Thanks are due to all the teachers and children who participated in this study. 


\begin{abstract}
This paper explores self-regulatory development in young children. Research suggests developmental differences in the acquisition of self-regulation, which could inform selfregulatory training at different ages. Most of this research focuses on very young children's (younger than 5) or older children's (aged 9+) self-regulation during academic tasks. This paper takes an innovative approach and investigates self-regulatory development in children aged 6 and 8 years old, in a developmentally appropriate and natural context: musical play. The findings indicate a quantitative increase in regulatory behaviours with age. A significantly higher increase is reported in monitoring, planning, and emotional/motivational monitoring compared to other regulatory behaviours. Socially-shared regulation shows steeper development than self-regulation and co-regulation. Regulatory abilities initially have a domain-specific element but gradually become fully general. These results have significant educational implications: instruction and training of self- and socially-shared regulation skills should start before the age of 8 , and tackle a diversity of tasks.
\end{abstract}

Keywords: self-regulation; self-regulatory development; metacognition; musical play; musicality. 


\section{Developmental differences in young children's self-regulation}

This paper investigates developmental differences in children's regulatory development. The paper argues that it is important to investigate developmental differences in the acquisition of self-regulation, because this can inform how teachers and practitioners support the development of self-regulation skills at different ages. Most research examines the development of self-regulation through academic tasks. This paper puts forward musical play as a developmentally appropriate, interesting and more natural context for the investigation of young children's developmental differences in self-regulation.

\section{Self-regulation: A Definition and an Introduction to Social Intentionality of Regulation}

Self-regulation's importance for the development of children as learners, children's educational achievement and their well-being later life (e.g. emotional problems and felony arrests) is often highlighted (Bronson, 2000; Hacker, Dunlosky, \& Graesser, 1998; Perry, 2013; Schweinhart \& Weikart, 1998). Self-regulation is defined as the monitoring and control of all aspects of human behaviour, including emotional, social and motivational elements (Boekaerts \& Niemivirta, 2000; Boekaerts \& Corno, 2005; Bronson, 2000; Pintrich, 2000), while acknowledging metacognition as the central cognitive element of self-regulation (Whitebread et al., 2010). The present study relies heavily on the model developed by Whitebread et al (2009), which suggests three areas of self-regulation: metacognitive knowledge (metacognition), metacognitive regulation and emotional/motivational regulation

(Figure 1). Each of the three areas of self-regulation comprises specific regulatory behaviours. Metacognitive knowledge (metacognition) refers to what people know about their cognition and entails three specific regulatory behaviours: the individual's knowledge about personal variables, task variables and strategy variables affecting their cognitive performance. Metacognitive regulation describes the metacognitive processes taking place 
during ongoing activities and involves four specific regulatory behaviours: planning, monitoring, control and evaluation. Finally, the area of emotional/motivational regulation comprises the monitoring or control of emotions and motivational states during tasks.

Currently, self-regulation research's focus has shifted to incorporate co-regulation and socially-shared regulation (Hadwin, Järvelä, \& Miller, 2011; Hadwin, Oshige, Gress, \& Winne, 2010). While self-regulation is defined as regulating one's own behaviours, coregulation and socially-shared regulation occur when coordination of self-regulation amongst self and others is required. Co-regulation occurs when coordination of self-regulation amongst self and others takes place in unequal situations, when one partner is very capable on a key aspect of the task and the other is not. On the contrary, socially shared regulation describes the egalitarian, interdependent or collectively shared regulation when a shared outcome is sought (Hadwin et al., 2010, 2011; Iiskala, Vauras, \& Lehtinen, 2004; Järvelä \& Hadwin, 2013). In the present study, despite using the term 'self-regulation', the social nature of children's regulation was explored on the three levels of self-, co-, and sociallyshared regulation as suggested by Hadwin et al. (2011) and Iiskala et al. (2004).

Most tasks investigated so far in self-regulation research were tasks performed by individuals. However, collaborative tasks are very prominent in real-life situations and the skill set required for these is currently gaining increasing attention in the school and work context (Organisation for Economic Co-operation and Development, 2013). During collaborative tasks, socially-shared regulation is often associated with higher performance and learning outcomes (Grau and Whitebread, 2012; Janssen, Erkens, Kirschner \& Kanselaar, 2012; Jarvela et al., 2013). Despite this, co-regulation and socially-shared regulation are often less prominent than self-regulation in children's group-work (Whitebread et al., 2007). It is thus important to explore how all three (self-, co-, and socially-shared regulation) develop in young children, in order to enable supporting their development. 
Importantly, this study has been inspired by the argument that there might be developmental differences in the acquisition and instruction of self-regulation skills (Zeidner, Boekaerts, \& Pintrich, 2000). Therefore, research investigating self-regulatory development is invaluable to understand what aspects of self-regulation have developed by what age and what areas require support. In this way it will be possible to identify age-appropriate approaches to support children's self-regulatory development.

\section{The Development of Self-regulation}

Historically, theories of self-regulation presumed that young children, below the age of 8, were not capable of self-regulatory behaviours (Veenman, Van Hout-Wolters, \& Afflerbach, 2006). Nevertheless, in the last 20-30 years, research suggests that very young children can self- and socially-regulate (Perry \& VandeKamp, 2000; Rodríguez \& Palacios, 2007; Vallotton, 2008; Whitebread, Bingham, Grau, Pino Pasternak, \& Sangster, 2007; Whitebread et al., 2009). The majority of developmental research in the area of selfregulation has been carried out with infants and very young children up to the age of five (e.g., Bernier et al., 2010; Rothbart et al. 2011; Shamir et al., 2009) or with older children (9 years and older), as evidenced below. Very little is known about the development of selfregulation between the ages of 6 and 8 years, which is otherwise widely acknowledged as a time period where a number of developments in metacognition take place (Flavell et al., 1966, 1997; Veenman et al., 2006). This paper focuses on addressing this gap.

Researchers exploring self-regulatory development have adopted two main approaches to explain the differences between different age groups. The first approach explores the development of self-regulation in the traditional, age-graded, maturational developmental perspective. The second approach investigates whether self-regulation is acquired in specific domains first and then generalised or vice-versa. 


\section{First approach: the development of self-regulation with age and maturation.}

Findings from studies looking at children from 5 to 15 years old have reported a quantitative and a qualitative increase in self-regulatory abilities as children grow up. For example, Van der Stel et al. (2010) collected think aloud protocols while 13 year old and 14 year old students solved math word problems and concluded that planning and evaluation, which are aspects of self-regulation (see Whitebread et al., 2009), increased with age (Bryce \& Whitebread, 2012; Van der Stel, Veenman, Deelen, \& Haenen, 2010).

With the exception of the afore-mentioned study, this maturational approach mainly focuses on two elements of self-regulatory behaviour, namely monitoring and control abilities. Monitoring skills are thought to be fairly established by 9 years of age, whereas control skills are still developing after age 9 (Roebers et al., 2009). The development of monitoring skills appears to be predominantly a maturational process, mostly dependent upon age and largely unaffected by developing ability, whereas the development of control depends upon ability. For example, Alexander, Carr and Schwanenflugel (1995), in an overview of existing literature exploring children's self-regulation in academic tasks, suggested that the development of control capabilities was accelerated in gifted children with superior IQs, while monitoring in these children only showed typical developmental improvements. This is consonant with the lack of differences in monitoring in text comprehension tasks between skilled and non-skilled readers (9- and 11-year-olds) reported by Eme, Puustinen and Coutelet (2006). This also agrees with Puustinen's (1998) finding that mathematical ability is more important than age for effective control strategies in problem solving tasks by 8 and 10-year-olds. More recently, Bryce and Whitebread (2012), moved to younger age-groups and observed 5- to 7-year-olds completing a train track task (a developmentally appropriate problem solving situation), and reported that monitoring 
processes improved with age, and control also improved with task specific ability, thus corroborating the previous findings.

\section{Second approach: domain-specific to general development of self-regulation or}

vice-versa? In the second approach, the literature presents the dilemma of whether selfregulation is acquired in a general way, following age-related, maturational changes and is then applied in specific domains, or if self-regulation initially develops in domain-specific contexts, perhaps related to domain-specific knowledge, and then generalises at a later stage (Pintrich \& Zusho, 2002; Van der Stel and Veenman 2010; Zeidner, et al., 2000) . However, as is made evident below, this research only focuses on the central cognitive element of selfregulation, that is metacognition.

On the one hand, as suggested by a review of earlier studies in Van der Stel and Veenman (2014), there is evidence for general metacognitive skills. For example, Veenman, Wilhelm, and Beishuizen (2004) found support for the generality of metacognitive skills. This study's findings suggested that when looking at 10-year olds, 12-year-olds, 14-year-olds and university students' performance on inductive learning tasks, metacognitive skilfulness manifested as a general, person-related characteristic across age groups. On the other hand, some studies suggest that metacognition is task-specific. An example is Thorpe and Satterly's (1990) research, which employed memory tasks with children aged 7 to 11 and has suggested that metacognition appears to be task-specific within this age range.

The latest development in this area suggests that metacognitive skills might be initially acquired within separate tasks and domains and then progressively become a generalised repertoire across tasks and domains. An example is Veenman and Spaans' (2005) study which employed math word problems and a biology task. In this study, metacognitive skills of the younger students (13-year-olds) appeared to be rather domain-specific, whereas those of the older ones (15-year-olds) turned out to be general by nature. Further research 
suggests that, until the age of 14 , the metacognitive skills of children have a substantial domain- or task-specific orientation. The same students may vary in metacognitive skills applied to reading, problem-solving, or discovery-learning tasks. Between the age of 14 and 15 years, however, metacognitive skills generalise across tasks and domains (Van der Stel \& Veenman, 2010, 2014; Veenman, 2015; Veenman \& Spaans, 2005).

Both these approaches informed this study's design, but the study was carried out in the novel context of musical play. The reasons for choosing the context of musical play are outlined below.

\section{Musical Play and Self-regulation: Why Study Self-regulation in a Musical Play context?}

Musical play entails vocalisations, rhythmic movement of the body and play with sound-making objects (Tarnowski, 1999; Young, 2005) while allowing for exploration, improvisation and creation with sound (Lew \& Campbell, 2005; Littleton, as cited in Tarnowski, 1999). In the present study, 'musical play' refers to the prevalent types of musical play in the literature: hand-clapping games, circle games, movement play, singing play and instrumental play (Harwood, 1998; Lew \& Campbell, 2005; Marsh \&Young, 2007; Tarnowski, 1999; Young, 2003, 2004).

Musical play's importance lies in the fact that it is a universal type of play, originating from the first interactions between infants and caregivers, the protoconversations, which are inherently musical and underpinned by biological predispositions (Papousek, 1996; Trevarthen, 2000; 2012; Young, 2005). Furthermore, because musical play appears very early in young children's lives, it allows for early expertise (Custodero, 2009) which could facilitate self-regulation.

Musical play is considered a potentially fertile context for self-regulation, given that it accumulates characteristics that have been shown to foster self-regulation in other contexts, 
such as its rule-based nature, intersubjectivity, scaffolding (Zachariou \& Whitebread, 2017). Inhibitory control is also prominent in musical play, and importantly, inhibitory control is also thought to support the development of self-regulation (Blair \& Ursache, 2011; Happaney, Zelazo, \& Stuss, 2004). For example, when a child engages in musical play, especially if playing with other children, she has to play in a very synchronised, interdependent way. She has to inhibit herself from playing her instrument whenever she would like, she has to wait for her turn to play, sing or dance. Despite these links, research studying musical play in relation to self-regulatory behaviours in children is scarce.

Music in general has been linked to emotional aspects of self-regulation in the past, mainly through studies looking at infants being on the receiving end of music, rather than actively involved in the play (amongst others Corbeil, Trehub, \& Peretz, 2016; Trehub, Ghazban, \& Corbeil, 2015). Studies looking at young children (rather than infants) or looking at all aspects of self-regulation (not just emotional) and that required children to be actively involved in music are mainly survey studies (Saarikalio, 2009; Williams, Barrett, Welch, Abad, \& Broughton, 2015). To the authors' best knowledge, research explicitly focusing on musical play, and all aspects of self-regulation through an observational approach is only now starting to emerge (Zachariou \& Whitebread, 2015, 2017; Winsler, Doucenne, \& Koury, 2011). However, none of these published studies has looked at the development of self-regulation. The present study aims to address this gap and focus on the development of self-regulation in musical play contexts.

In addition, musical play appears to be a very promising ground for studying the social nature and intentionality of regulatory episodes. This is because musical play is distinct for its inherent social nature and the unique opportunities it provides to children for group-work, highly synchronised collaboration and interdependence (Zachariou \& Whitebread, 2017; Harwood and Marsh, 2012; Pound, 2010). Therefore, the present study 
aims to explore the developmental differences of children's regulation not only at the selfregulation level but also in relation to the social nature of children's regulation.

\section{The Current Study}

The current study's aims have been inspired by the two approaches in studying the development of self-regulation: 1) studying the development of self-regulation with age and maturation and 2) studying whether self-regulation is acquired in a domain-specific to general way or vice-versa.

Studies on young children's self-regulatory development have mostly looked at children younger than 5 or older than 8 years old. As evident from the two afore-mentioned approaches, most studies focused on monitoring and control or metacognition rather than looking at all aspects of self-regulation, employed academic tasks which were not necessarily interesting or meaningful to the children and were plagued by an over-reliance on children's language skills and the assumption that children are fully conscious of the skills they use (Bryce and Whitebread, 2012). The present study addressed these weaknesses and aimed to look at children aged 6 to 8 years old, explore all aspects of self-regulation (in addition to cognitive monitoring and control, we explored metacognitive knowledge, planning, evaluation, emotional/motivational monitoring and control), in the context of musical play which is thought to be a meaningful and interesting context for young children, and adopted an observational approach.

The first research question addressed the first research aim, to explore any developmental differences in children's regulatory development through musical play:

RQ1: How does regulatory behaviour during musical play vary between 6- and 8-year-old children?

We addressed this question by testing out the following two hypotheses: 
Hypothesis 1.1: Different regulatory behaviours appear at different rates in the two age groups

The first hypothesis aimed to investigate the development of all aspects of selfregulation, rather than only monitoring and control as has been done in the past. The second hypothesis acknowledged the current research focus on the social nature of regulation. It thus focused on investigating the development of self-, co- and socially-shared regulation.

Hypothesis 1.2: Regulatory behaviours of different social intentionality appear at different rates in the two age groups

The second approach to researching self-regulatory development inspired the second aim of this paper to explore whether regulatory abilities develop in specific domains at first and then become generalised or vice versa. With this in mind, and inspired by Van der Stel and Veenman's (2014) suggestion that metacognitive abilities are general, and that they move from having a smaller domain-specific element to gradually becoming less domain-specific and fully general, we posed the second research question:

RQ2: Does self-regulation first develop in a domain-specific way before it is generalised?

In order to address this question, we tested out two hypotheses. The first hypothesis stated that in younger children, self-regulation during musical play would be positively correlated with the domain specific abilities related to musical play, i.e. children's musicality. However, since we expected that self-regulation would be generalised in older children, we did not expect this correlation to be evident in older children.

Hypothesis 2.1: Regulatory behaviours during musical play are positively correlated with musicality in the 6-year-olds, but not in the 8-year-olds.

According to Van der Stel and Veenman's (2014) position, we also expected that selfregulation in younger children would have a domain specific element and self-regulation in 
older children would be more general. Thus, we expected that older children's selfregulation in musical play would be highly related to their general self-regulation abilities, whereas for younger children this correlation would be less strong.

Hypothesis 2.2: The positive relationship between self-regulatory behaviour in general and regulatory behaviour during musical play is stronger in 8-year-olds than in 6-year-olds.

\section{Method}

In accordance with the present study's aims, we adopted a cross-sectional design, since comparing different age groups enables mapping of the developmental differences in children's regulatory development through musical play. The study was based on observational methods. Five different mainstream primary schools participated in this study. Three classes of 6-year-olds (Year 1) and three classes of 8-year-olds (Year 3) participated in five musical play sessions over five weeks, and we focused on a total of 36 children. During these classes, we video-recorded six children from each class. We coded the observations for regulatory behaviours, on the basis of a coding framework. Furthermore, we assessed children's general regulatory behaviour on a task-based assessment (SBOS) and we collected data on children's musicality through the Primary Measures of Music Audiation test (PMMA).

\section{Sample}

More than 15,000 micro-episodes of regulatory behaviours during musical play were analysed for the purposes of this study. A micro-episode is a point event, i.e., a behaviour without measurable or relevant duration where only its occurrence is of interest. These microepisodes were spread over 34 hours of video-recording of clear musical play episodes coming from 36 (nationality removed for anonymity purposes) children. The musical play sessions were filtered and only episodes of clear musical play underwent coding, i.e., episodes where 
children were actively and evidently engaged in musical play. On average, each child was purely engaged in clear musical play for 56 minutes in total. During this time each child engaged in 437 regulatory behaviours on average.

Eighteen children were in Year $1\left(M_{\text {age }}=6.5\right.$ years, age range: $5.8-6.8$ years $)$, and 18 were in Year 3 ( $M_{\text {age }}=8.4$ years, age range: $8.1-8.9$ years). The children were chosen on the basis of criterion sampling. In both age-groups half of the children were girls and there was a similar number of children at all levels of regulation (12 low-regulated, 13 medium-regulated, 11 highly-regulated).

Informed consent was granted by all the participants, before the start of this study. In the case of children participants, third party consent (from parents or guardians) was obtained on their behalf.

\section{Research Design}

Musical play sessions. Each of the five musical play sessions lasted approximately 30 minutes, focused on one of the five prevalent types of musical play: hand-clapping games, circle games, movement play, singing play and instrumental play, and followed predetermined lesson plans. The hand-clapping games session was an opportunity for the children to play call and response games with the teacher (e.g. the teacher claps a rhythm and they copy her), play hand-clapping games they already knew and learn new hand-clapping games, which they could also adapt as they wanted. The circle games session comprised games where the children were holding hands and singing in a circle and had to dance in a circle or imitate the person in the middle of the circle. Movement play entailed activities such as dancing to the rhythm the teacher was playing, or dancing to musical pieces on their own or in groups of three. Singing and instrumental play included call and response games (with the voice and with the music instruments respectively) and the children playing with their 
voices (and finger puppets)/ their music instruments, with the aim to create their own song/musical piece. More information on these activities can be found in Zachariou \& Whitebread (2017).

The play tasks introduced to the children contained elements of free play, yet mainly afforded 'guided play' (i.e., play sensitively and responsively guided by an adult, within a meaningful for the children context). Extensive research advocates for guided play being a powerful tool for teaching and learning, with catalytic effects on children's intellectual, emotional, social, and linguistic development (Golinkoff, Hirsh-Pasek, \& Singer, 2008; Hirsh-Pasek, Golinkoff, Berk and Singer, 2008).

The musical play sessions mainly entailed play that was initiated by the teacher but led by the children to any direction they wanted. For example, the teacher would ask the children whether they knew of any circle musical games and then encourage them to play the games they knew. A few child-initiated and led or teacher-initiated and led play activities also took place. The children were allowed long, unbroken periods of time (Smidt, 2011) and plenty of space to 'play about' with sounds, to practise and explore (Pound, 2010). Additionally, it was crucial for the study's validity to confirm that the children perceived the activities as play. Therefore, we took into consideration research on what children themselves define as play because when children are engaged in an activity they regard as play their behaviour changes and becomes potentially more facilitating for regulatory behaviours, and their learning potentials are amplified (Howard, 2010).

It is important to note that all types of musical play (singing, instrumental and movement play, hand-clapping and circle games) and all sources of initiation and leadership (teacher initiated and led, teacher initiated but child led, child initiated and led) afforded for the emergence of regulatory behaviour. 


\section{Measures.}

Children's regulation during musical play: Coding framework. We devised and employed an observational framework to code the regulatory behaviours observed during musical play. We constructed this coding framework on the basis of the CIndLe coding framework (Whitebread et al., 2009). The CIndLe coding framework serves for identifying verbal and non-verbal indicators of different regulatory behaviours in young children. It enables identifying and coding all the areas and specific types of regulation (presented in Figure 1): behaviours of metacognitive knowledge (metacognitive knowledge of persons, tasks and strategies), metacognitive regulation (planning, monitoring, control and evaluation) and emotional and motivational regulation (emotional/motivational monitoring or control). Examples of different specific types of regulatory behaviour as observed during musical play are provided in Appendix A. The CIndLe has been validated and internationally used in observing children up to the age of 9 (Zachariou \& Whitebread, 2015; 2017; Jokić \& Whitebread, 2011; Whitebread \& Cárdenas, 2012). In order to investigate the second hypothesis of the first research question, we added a feature allowing to additionally code for the social intentionality of each regulatory behaviour: whether it was self-, co- or sociallyshared regulation (adapted from Grau \& Whitebread, 2012; Hadwin et al., 2010, 2011; Iiskala et al., 2004). Examples of the social intentionality of regulatory behaviours as observed in musical play can be found in Appendix B.

We coded the data on children's regulatory behaviours during musical play on the Observer XT10 software and we extracted the rates of the behaviours through behaviour analysis, following a detailed protocol analysis procedure. Whenever a regulatory behaviour was identified, it was coded as a point event, defined as to the type of regulatory behaviour (one of the nine main codes) and as to its social intentionality. For example, a child directing who of his peers plays which instrument and when would be coded as showing planning - 
metacognitive regulation (type of regulatory behaviour) and co-regulatory (social intentionality) behaviour. Lastly, we calculated the frequency of each observed regulatory behaviour per minute of musical play, for each child separately. For example, if a child engaged in eight planning behaviours within four minutes of musical play, her rate of planning behaviours would be 2 regulatory behaviours/minute. The quantitative analysis was predominantly based on these rates.

A second observer independently coded more than $10 \%$ of the data. Percentages of agreement for unitizing the data (i.e., agreeing on which units of behaviour should be coded) were above $69 \%$ and Cohen's Kappa (to establish whether the dually coded behaviours were assigned the same codes) was $\mathrm{k}=.89$, both comparing favourably with similar studies (Whitebread et al., 2009).

Children's general regulation: SBOS. We chose the Strategic Behaviour Observation Scale (SBOS) as the most suitable direct, task-based measure of children's general self-regulation. This is a structured observation instrument used to assess typically developing children's self-regulation when engaged with a cube assembly task (Dermitzaki, Leondari, \& Goudas, 2009). The SBOS assessment required the children to engage in a playful task where they were shown models and asked to reproduce them, using cubes. We allowed each child approximately 40 minutes to complete as many tasks as he/she could, at his/her own pace, and we video-recorded the procedure. The researcher retrospectively watched the tasks and coded each task for cognitive, metacognitive and motivational/volitional strategic behaviours, assigning a score from 1 to 4 for each behaviour based on the criteria provided by Dermitzaki et al. (2009). We then calculated the score for each behaviour as a mean, adjusted to how many tasks the child had completed. Then the sum of the means was divided by the number of behaviours to find the final score for each child. For inter-reliability purposes, a second observer coded $20 \%$ of the data. The intraclass 
correlation coefficient was .98 , illustrating an extremely high consistency between the two observers.

Children's musicality: PMMA. The Primary Measures of Music Audiation (PMMA) (Gordon, 1979) test assesses musical aptitude: perceiving and giving meaning to sound through tonal and rhythmic patterns. Each of its two tests lasts 20 minutes and comprises 40 questions. For each question, children listen to two phrases and are then asked to mark their sheets according to whether the two phrases sound the same or different. For the purposes of RQ2, we used the PMMA composite percentile score, which is a standardised score. We chose the PMMA as one of the most prevalent assessments for musicality in current use and the only one devised for typically developing children aged 4 to 8 years. Additionally, the PMMA has high reliability for 6-year-olds (test-retest: $r=.75$ and split-half reliability: $r=.92$ ) and for 8-year olds ( $r=.73$ and $r=.90$ respectively). High concurrent validity has also been reported for the PMMA, since 227 fourth grade children's scores on the Musical Aptitude Profile were correlated with their PMMA scores ( $r=.71)$ (Gordon, 1979).

\section{Statistical Analysis}

All the parametric assumptions were checked. The assumption of normality was tenable for most variables with a few, mostly marginal, exceptions. Acknowledging this and the study's small sample size, both the parametric and non-parametric alternatives were run for all statistical tests. When these produced different results, or when there were indications for more than one violation of assumptions, a square root transformation was applied or the non-parametric results were reported (depending on the nature of the test).

For the purposes of the first research question, we run an independent samples t-test and a Mann-Whitney test to statistically examine whether the frequency of emergence of regulatory behaviours was significantly different between 6- and 8-year-olds. We also 
conducted mixed-design ANOVAs $(2 \times 3$ and $2 \times 9)$ to explore the differences between different regulatory behaviours (repeated-measures variables) and between different agegroups (between-group variables). The ANOVAs that indicated significant differences were always followed up by post-hoc tests to which a Bonferroni correction was applied, and interaction effects were explored through contrasts. For the second research question, Pearson's $r$, one-tailed correlation and the Spearman's Rho non-parametric statistic (onetailed) was calculated separately for each age-group. One-tailed tests were conducted, given that the hypotheses explored were all directional.

\section{Results}

\section{RQ1: How does Regulatory Behaviour during Musical Play Vary Between 6 and 8- year-old Children?}

The rate of overall regulatory behaviours per minute per child during musical play is higher in 8-year-old children than it is in 6-year-old children. In order to statistically examine whether the frequency of emergence of regulatory behaviours is significantly different between 6- and 8-year-olds, both an independent samples t-test and a Mann-Whitney test were run. On average, children aged $8(M=8.86, S E=.56)$ show significantly more regulation during musical play than children aged $6(M=6.73, S E=.44), t(34)=-3.01, p=$ .005. This finding represents a small to medium effect size, $r=.21$, which could potentially be explained by the study's sample size and cross-sectional nature, which reduces the power of analyses conducted (further discussed in Limitations and Future Research).

Hypothesis 1.1: Different regulatory behaviours appear at different rates in the two age groups 
For the purposes of this study it was meaningful to examine whether different areas of regulatory behaviour and different specific regulatory behaviours appeared at different rates in the two age groups.

There is a significant interaction effect between the age of the child and the area of regulatory behaviour, $F(1.14,38.70)=6.55, p=.01$, a result that is evident in Table 1 , and is corroborated by multivariate tests, $V=0.28, F(2,33)=6.42, p=.004$.

The contrasts reveal significant interactions when comparing 6- and 8-year-old children's rates of metacognitive knowledge to metacognitive regulation, $F(1,34)=7.81, p$ $=.008$ and to emotional/motivational regulation, $F(1,34)=12.71, p=.001$. This is depicted in the interaction graph in Figure 2, which shows that the rates of metacognitive regulation behaviours and emotional/motivational regulation increase significantly more between age 6 and 8 than the rates of metacognitive knowledge behaviours.

There is also a significant interaction effect between the age of the child and the specific type of regulatory behaviour, $F(5.18,175.96)=5.02, p<.001$, a result that is confirmed by multivariate tests, $V=0.61, F(8,27)=5.37, p<.001$. As presented in Table 2, the rates of all the specific regulatory behaviours are higher in 8-year-olds than in 6-yearolds.

The contrasts reveal significant interactions (Figure 3) when comparing 6- and 8-yearold children's rates of monitoring to metacognitive knowledge of persons, $F(1,34)=12.51, p$ $=.001$, to metacognitive knowledge of tasks, $F(1,34)=10.10, p=.003$, to metacognitive knowledge of strategies, $F(1,34)=9.36, p=.004$, to control, $F(1,34)=12.01, p=.001$, to evaluation, $F(1,34)=6.95, p=.01$, and to emotional/motivational control, $F(1,34)=12.75, p$ $=.001$. The remainder of the interactions are reported as non-significant. 
Therefore, monitoring, planning and emotional/motivational monitoring behaviours are reported to show a significantly greater increase between 6- and 8-year-olds compared to all other specific regulatory behaviours.

Hypothesis 1.2: Regulatory behaviours of different social intentionality appear at different rates in the two age groups

Regarding the emergence of regulatory behaviours of different social intentionality (self-, co- and socially-shared regulation, Table 3), there is a significant interaction effect between the age of the child and the social intentionality of regulatory behaviour, $F(1.82$, $61.91)=3.38, p=.045$. It should be underlined that this is only a marginally significant effect and this is corroborated by the results of multivariate tests, which show that the rate of regulatory behaviours according to the social intentionality of regulation is not significantly different between 6-year-olds and 8-year-olds, $V=0.13, F(2,33)=2.39, p=.11$.

There is only one significant interaction: when comparing 6- and 8-year-old children's rates of socially-shared regulation to self-regulation rates, $F(1,34)=4.91, p=.03$ (Figure 4). This analysis illustrates that even though older children in general showed more self-regulatory, co-regulatory and socially-shared regulation behaviours than younger children during musical play, there is a greater increase for socially-shared regulatory behaviours.

\section{RQ2: Does Self-regulation First Develop in a Domain-specific Way Before it is}

\section{Generalised?}

In order to explore this research question, two separate hypotheses were posed.

Hypothesis 2.1: Regulatory behaviours during musical play are positively correlated with musicality in the 6-year-olds, but not in the 8-year-olds. 
In order to explore this hypothesis, correlations were run between musicality scores (PMMA Composite Percentile) and the frequency of regulatory behaviours during musical play, separately for each age group.

The hypothesis is supported. The 6-year-old children's musicality is positively and significantly correlated with their regulatory behaviours during musical play, $r=.46, p$ (onetailed) $=.03$. On the other hand, the 8 -year-old children's musicality is not significantly related to their regulatory behaviours during musical play, $r_{s}=.22, p($ one-tailed $)=.19$.

Hypothesis 2.2: The positive relationship between self-regulatory behaviour in general and regulatory behaviour during musical play is stronger in 8-year-olds than in 6-year-olds.

In order to further explore whether self-regulation first develops in a domain-specific way and is then generalised, we hypothesised that there would be a difference between 6year-old and 8-year-old children in the correlations of general self-regulatory abilities with regulatory behaviour during musical play. The Spearman's Rho non-parametric statistic (one-tailed) was calculated separately for each age-group.

The results are surprising. Amongst the 6-year-old children, the correlation between self-regulation in general and regulation during musical play, $r_{s}=.72, p$ (one-tailed) $<.001$, is seemingly higher than the same correlation in 8-year-old children, $r_{s}=.57, p$ (onetailed)=.007. It could be argued that children's general self-regulatory ability can account for more variance in the ranks of regulatory behaviours during musical play in 6-year-old children $\left(52 \%\right.$ of variance, $\left.\mathrm{R}^{2}=.52\right)$ than it does in 8 -year-old children $\left(32 \%\right.$ of variance, $\mathrm{R}^{2}=$ .32). Nonetheless, when this difference in the levels of correlation between 6-year-olds and 8-year-olds is checked statistically there does not appear to be a significant difference between the two. The $\mathrm{Z}_{\text {Difference }}$ is .74 , therefore the one-tailed probability value is .23 (in two-tailed probability =.46). As such, the correlation between general self-regulatory ability 
and regulatory behaviour during musical play is not significantly different in 6-year-old and 8-year-old children. Thus, this hypothesis is not supported.

In an overview of the findings under RQ2, the fact that children's general selfregulation is significantly related to children's self-regulation during musical play in both the age groups (Hypothesis 2.2), but musicality was only related to the 6-year-old's selfregulation during musical play (Hypothesis 2.1) leads to the conclusion that children's regulatory abilities are general, and that they move from having a smaller domain-specific element to gradually becoming less domain-specific and fully general.

\section{Discussion}

This paper reported some intriguing results. Apart from the expected result that evidence of regulatory behaviour increased quantitatively between 6 and 8 years of age, the results also indicated that not only monitoring, but also planning and emotional/motivational monitoring develop between these ages. In addition to this, all self-, co and socially shared regulation appeared more frequently in 8-year-olds rather than 6-year-olds, with socially shared regulation showing a steeper increase. Finally, the results revealed that children's regulatory abilities are general, and that they move from having a smaller domain-specific element to gradually becoming less domain-specific and fully general.

\section{Regulatory Behaviour Increases Quantitatively Between 6 and 8 Years of Age}

Older children showed a significantly higher rate of regulatory behaviours (areas of regulation and specific regulatory behaviours) during musical play compared to the younger children. This is closely aligned with previous research, which has argued that children's regulatory abilities develop with time (Bryce \& Whitebread, 2012; Thorpe \& Satterly, 1990; Van der Stel et al., 2010; Van der Stel \& Veenman, 2010). It was therefore an expected result, as was the finding that metacognitive regulation and emotional/motivational regulation 
behaviours are developing between 6 and 8 years of age. These findings also provide further evidence to contest Van der Stel and Veenman's (2010) view that the onset of metacognitive skill development for academic tasks is not expected before the age of 8-10 years. These robust findings were made possible thanks to employing musical play as a context that was developmentally appropriate, interesting and meaningful to the children, and as a context that elicited self-regulation through its rule-based, intersubjective nature and the opportunities it afforded for inhibitory control.

In addition, we could argue that we reached these results thanks to the coding framework's ability to detect non-verbal indications of self-regulation, in comparison to previous studies' over-reliance on children's language skills. The results also suggested that metacognitive knowledge regulation probably remains stable between 6 and 8 years of age or is possibly also being developed but at a slower rate. However, this result could also only be indicating that observable behaviours indicating metacognitive knowledge remain at the same level. This could be linked to a flaw in the measurement tools used for this study, particularly as far as metacognitive knowledge is concerned. Even though metacognitive knowledge is mainly evident through verbalisations (see CIndLe coding scheme, Whitebread et al., 2009), there was no opportunity in the present study to ask the children to elaborate on their behaviour. Therefore, in comparison to other areas which are also evident through nonverbal means, the measurement of metacognitive knowledge was at a disadvantage. An adaptation that would allow for examining metacognitive knowledge behaviours would involve prompting this through carefully structured questions, possibly in interviews with the children following the musical play tasks.

Beyond just looking at monitoring and control. Given that most studies so far have solely focused on control and monitoring, it is important to highlight that this was the first study with results on the remainder specific regulatory behaviours. It thus appears that not 
only monitoring (as has been highlighted in the literature so far), but also planning and emotional/motivational monitoring behaviours develop between 6 and 8 years of age compared to all other specific regulatory behaviours. The literature has argued that the development of monitoring skills could be explained by a maturational process unaffected by ability, in comparison to control and metacognitive knowledge processes, which have been related to ability (e.g., Alexander et al., 1995; Bryce \& Whitebread, 2012). Given that both age groups comprised children at different levels of musical and regulatory ability, this finding largely resonates with the literature, while it extends the literature by suggesting that the development of planning and emotional/motivational monitoring behaviours could also be viewed as a maturational process.

Development of co-regulation and socially-shared regulation. This study was the first to attempt to shed light on the development of co- and socially-shared regulation, compared to all other developmental studies that focus on self-regulation only. The findings indicated that alongside with the ability to self-regulate, the abilities to co-regulate and engage in socially-shared regulation also develop between 6 and 8 years of age. In fact, the ability to share regulation between group members shows steeper development in this time period, than the abilities to self- and co-regulate.

\section{Children's Regulatory Abilities are General and Move from Having a Smaller Domain- specific Element to Gradually Becoming Fully General}

In terms of domain specific versus general development of self-regulation, this was the first study to explore the development of all aspects of self-regulation and not just the cognitive element (metacognition).

The results of Hypothesis 2.1 provide indications that children's domain-specific knowledge (musicality) is related to their ability for self-regulation at the younger age, but 
not when they are older where the regulatory abilities might be more generalised. Most importantly, this could potentially show that development of children's regulatory abilities is more related to domain-specific knowledge at an early age (for example at 6 years), and later develops in a more generalised way (for example at 8 years). This corroborates Veenman and Spaans' (2005) assumption, but also provides evidence that this takes place at a younger age than they suggested and on wider aspects of self-regulation rather than just on metacognition. These findings, at least partially, conflict with the claims by Thorpe and Satterly (1990) that regulation is task-specific in children aged 7-11 years. However, the results of Hypothesis 2.2 indicate that self-regulation is developed in a general way. As a whole, these findings corroborate the developmental trajectory that was expected according to metacognition research (van der Stel \& Veenman, 2014), and point in the direction of children's regulatory abilities being general (2.2), and that they move from having a smaller domain-specific element at a younger age, to gradually becoming less domain-specific and fully general when children are older (2.1).

\section{Implications}

The study's pioneering methodology of exploring young children's self-regulation development through observing their verbal and non-verbal behaviours during developmentally appropriate, interesting and meaningful activities in the form of musical play, could inform the literature on self-regulation development by enabling researchers to study all aspects of self-regulation and move towards younger children. This methodology could equally inform other areas of developmental psychology. The literature on selfregulation and music, which focuses on experts or children undertaking formal tuition (e.g., Chaffin \& Logan, 2006; McPherson \& Renwick, 2001), may also benefit from this approach. 
Both this study's main findings could have significant educational implications. The first finding that suggests that monitoring, planning and emotional/motivational monitoring is a maturational skill unaffected by ability, brings a hopeful message for educational contexts: monitoring and planning are not predetermined by a child's task-specific ability and could potentially be improved with more opportunities for engagement in tasks encouraging monitoring and planning. In addition, the trends reported in this paper, regarding a steep development of monitoring between 6 and 8 years of age agree with Roebers and colleagues' (2009) results that monitoring skills are fairly established by age 9. It could thus be suggested that emphasis should be placed on the development of monitoring skills before the age of 9 .

On a separate note, any subsequent interventions aiming to improve children's control and metacognitive knowledge (which according to our findings are related to ability) should additionally target the children's task-specific abilities. Equally, our results that control develops less steeply between 6 and 8 years corroborate Roebers et al.'s (2009) suggestion that control is more likely to develop further after age 8 , and suggest that attention to the development of control should continue after the age of 8 . Further to this, the result that the ability to share regulation between group members showed steeper development in this time period, than the abilities to self- and co-regulate, could inform educational practice. To further support this development, teachers should provide ample opportunities for pupils to engage in cooperative activities that afford interdependency and intersubjectivity (such as musical play, Zachariou \& Whitebread, 2017) and encourage socially-shared regulation before age 8 .

The second finding, that self-regulatory skills are general, with a smaller domainspecific element at a younger age before they become generalised, has implications for the instruction, training and transfer of self-regulatory skills across domains. To overcome the challenge that domain-specific self-regulatory skills merge into generalised self-regulatory 
skills in the course of development, it has been suggested that instruction and training of selfregulatory strategies and skills should tackle a diversity of tasks (Pressley \& Gaskins, 2006; Veenman et al., 2004). In this way, generalising or synchronizing skills across tasks and disciplines will be encouraged. Considered together, the findings suggest that this selfregulation training in a variety of tasks should take place at the youngest ages below 8 (when self-regulatory abilities are still partly domain-specific), and not be left for children between 13 to 15 as has been previously suggested (Veenman, 2015). This suggestion resonates with previous findings that younger students (grade one to three) show greater effects following interventions (Dignath, Buettner, \& Langfeldt, 2008; Hattie, Biggs, \& Purdie, 1996).

\section{Limitations and future research}

It must be acknowledged that because of the particularity of this sample and context, the findings presented here can only be understood within the specific population and the framework of the tasks employed. The cross-sectional design of this study also presented some limitations. This design provided snapshots of points in development using two different groups of children. Consequently, the risk in drawing developmental conclusions solely from this cross-sectional design is high, and causality cannot be discussed. Moreover, in order to draw developmental conclusions, groups should ideally be matched, for instance in terms of socio-economic status and abilities. In the present study, even though data on the children's socio-economic status was not collected from schools, an effort was made to match the two age-groups on general regulatory abilities and sex. Therefore, although the groups of participants were not identical, they were fairly well-matched to one another. However, while this study focused on presenting the differences between younger and older children, conclusions on the developmental path involved can only be drawn very tentatively.

Due to the small sample size and the study's cross-sectional nature, the types of possible statistical analyses were limited, and the power of analyses was somewhat reduced. 
Further studies should opt for a larger sample size to strengthen the statistical results and their generalisability. Future research could extend the aims of this project, by recruiting more participants, including children of different age groups, in different countries and assessing children's self-regulation in a variety of contexts, and could also follow a longitudinal approach, which would be more appropriate for drawing developmental conclusions.

\section{Conclusion}

This paper is the first to explore the developmental differences in young children's regulatory development, in the context of interesting, meaningful and developmentally appropriate activities for the children. Through implementing a cross-sectional approach and focusing on 6 and 8-year-old children, we suggest that children's regulatory abilities develop between 6 and 8 years of age. We explored all aspects of self-regulation and we found that monitoring, planning and emotional/motivational monitoring develop in a maturational way, unrelated to ability. Furthermore, the results suggest that socially-shared regulation develops significantly more steeply compared to the ability for self-regulation and co-regulation. Finally, the findings suggest that regulatory abilities are general but are also more influenced by domain-specific knowledge and abilities (such as musicality) at a younger age and become more generalised at a later stage. It is thus important that instruction and training of self-, coand socially-shared regulatory strategies and skills should start before the age of 8 , tackle a diversity of tasks and, in the case of interventions aiming to improve children's control and metacognitive knowledge, also target the children's task-specific abilities. Most importantly, all this should take place in contexts that are natural, meaningful and interesting for the children. 


\section{References}

Alexander, J. M., Carr, M., \& Schwanenflugel, P. J. (1995). Development of metacognition in gifted children: Directions for future research. Developmental Review, 15(1), 1-37. doi: 10.1006/drev.1995.1001

Bernier, A., Carlson, S. M., \& Whipple, N. (2010). From external regulation to selfregulation: Early parenting precursors of young children's executive functioning. Child development, 81(1), 326-339.

Blair, C., \& Ursache, A. (2011). A bidirectional model of executive functions and selfregulation. Handbook of self-regulation: Research, theory, and applications, 2, 300320.

Boekaerts, M., \& Corno, L. (2005). Self-regulation in the classroom: A perspective on assessment and intervention. Applied Psychology, 54(2), 199-231. doi:10.1111/j.1464-0597.2005.00205.x

Boekaerts, M., \& Niemivirta, M. (2000). Self-regulated learning: Finding a balance between learning goals and ego-protective goals. In M. Boekaerts, P. Pintrich, \& M. Zeidner (Eds.), Handbook of self-regulation (pp. 417-450). San Diego, CA: Academic.

Bronson, M. (2000). Self-regulation in early childhood: Nature and nurture. New York: Guilford Press.

Bryce, D., \& Whitebread, D. (2012). The development of metacognitive skills: evidence from observational analysis of young children's behaviour during problem-solving. Metacognition and Learning, 7(3), 197-217. doi: 10.1007/s11409-012-9091-2

Chaffin, R., \& Logan, T. (2006). Practicing perfection: How concert soloists prepare for performance. Advances in Cognitive Psychology, 2(2-3), 113-130.

Corbeil, M., Trehub, S. E., \& Peretz, I. (2016). Singing delays the onset of infant distress. Infancy, 21(3), 373-391. doi: 10.1111/infa.12114 
Custodero, L. (2009). Intimacy and reciprocity in improvisatory musical performance: Pedagogical lessons from adult artists and young children. In S. Malloch \& C. Trevarthen (Eds.), Communicative Musicality. Exploring the basis of human companionship (pp. 513-529). Oxford: Oxford University Press.

Dermitzaki, I., Leondari, A., \& Goudas, M. (2009). Relations between young students' strategic behaviours, domain-specific self-concept, and performance in a problemsolving situation. Learning and Instruction, 19(2), 144-157. doi:10.1016/j.learninstruc.2008.03.002

Dignath, C., Buettner, G., \& Langfeldt, H.P. (2008). How can primary school students learn self-regulated learning strategies most effectively? A meta-analysis on self-regulation training programmes. Educational Research Review, 3(2), 101-129. doi:10.1016/j.edurev.2008.02.003

Eme, E., Puustinen, M., \& Coutelet, B. (2006). Individual and developmental differences in reading monitoring: When and how do children evaluate their comprehension? European Journal of Psychology of Education, 21(1), 91-115. doi:0.1007/BF03173571

Flavell, J. H., Beech, D. R., \& Chinsky, J. M. (1966). Spontaneous verbal rehearsal in a memory task as a function of age. Child Development, 37, 283-299.

Flavell, J. H., Green, F. L., Flavell, E. R., \& Grossman, J. B. (1997). The development of children's knowledge about inner speech. Child Development, 68, 39-47.

Golinkoff, R., Hirsh-Pasek, K., \& Singer, D. (2008). Why Play = Learning: A challenge for parents and educators. In D. Singer, R. Golinkoff, \& K. Hirsh-Pasek (Eds.), Play= Learning. How play motivates and enhances children's cognitive and socialemotional growth (pp. 3-15). New York: Oxford University Press.

Gordon, E. (1979). Primary Measures of Music Audiation. Chicago, IL: GIA. 
Grau, V., \& Whitebread, D. (2012). Self and social regulation of learning during collaborative activities in the classroom: The interplay of individual and group cognition. Learning and Instruction, 22(6), 401-412. doi:10.1016/j.learninstruc.2012.03.003

Hacker, D., Dunlosky, J., \& Graesser, A. (Eds.). (1998). Metacognition in educational theory and practice. London: Lawrence Erlbaum.

Hadwin, A. F., Järvelä, S., \& Miller, M. (2011). Self-regulated, co-regulated, and socially shared regulation of learning. In B.J. Zimmerman, \& D.H.Schunk (Eds.), Handbook of Self-Regulation of Learning and Performance (pp. 65-86). New York: Routledge.

Hadwin, A. F., Oshige, M., Gress, C. L., \& Winne, P. H. (2010). Innovative ways for using gStudy to orchestrate and research social aspects of self-regulated learning. Computers in Human Behaviour, 26(5), 794-805. doi: 10.1016/j.chb.2007.06.007

Happaney, K., Zelazo, P. D., \& Stuss, D. T. (2004). Development of orbitofrontal function: Current themes and future directions. Brain and cognition, 55(1), 1-10.

Harwood, E. (1998). Music learning in context: A playground tale. Research Studies in Music Education, 11(1), 52-60. doi: 10.1177/1321103X9801100106

Harwood, E., \& Marsh, K. (2012). Children's ways of learning inside and outside the classroom. In G. McPherson \& G. Welch (Eds.), The Oxford Handbook of Music Education (pp. 322-340). New York: Oxford University Press.

Hattie, J., Biggs, J., \& Purdie, N. (1996). Effects of learning skills interventions on student learning: A meta-analysis. Review of Educational Research, 66(2), 99-136. doi:10.3102/00346543066002099

Hirsh-Pasek, K., Golinkoff, R., Berk, L. E., \& Singer, D. (2008). A mandate for playful learning in preschool: presenting the evidence. New York: Oxford University Press. 
Howard, J. (2010). The developmental and therapeutic potential of play: Re-establishing teachers as play professionals. In J. Moyles (Ed.), The excellence of play (3rd ed., pp. 201-215). Maidenhead: Open University Press.

Iiskala, T., Vauras, M., \& Lehtinen, E. (2004). Socially shared metacognition in peerlearning? Hellenic Journal of Psychology, 1, 147-178.

Janssen, J., Erkens, G., Kirschner, P. A., \& Kanselaar, G. (2012). Task-related and social regulation during online collaborative learning. Metacognition and Learning, 7(1), $25-43$.

Järvelä, S., \& Hadwin, A. F. (2013). New frontiers: Regulating learning in CSCL. Educational Psychologist, 48(1), 25-39.

Järvelä, S., Järvenoja, H., Malmberg, J., \& Hadwin, A. F. (2013). Exploring socially shared regulation in the context of collaboration. Journal of Cognitive Education and Psychology, 12(3), 267.

Jokić, C. S., \& Whitebread, D. (2011). The role of self-regulatory and metacognitive competence in the motor performance difficulties of children with developmental coordination disorder: a theoretical and empirical review. Educational Psychology Review, 23(1), 75-98. doi: 10.1007/s10648-010-9148-1

Lew, J. C.T., \& Campbell, P. S. (2005). Children's Natural and Necessary Musical Play: Global Contexts, Local Applications. Music Educators Journal, 91(5), 57-63.

Marsh, K., \& Young, S. (2007). Musical Play. In G. McPherson (Ed.), The child as musician: A handbook of musical development. (pp.289-310). USA: Oxford University Press.

McPherson, G. E., \& Renwick, J. M. (2001). A longitudinal study of self-regulation in children's musical practice. Music Education Research, 3(2), 169-186. doi: $10.1080 / 14613800120089232$ 
Organisation for Economic Co-operation and Development. (2013, March). PISA 2015: Draft collaborative problem solving framework. Retrieved from http://www.oecd.org/pisa/pisaproducts/DraftPISA2015CollaborativeProblemSolvingF ramework.pdf

Papousek, H. (1996). Musicality in infancy research: biological and cultural origins of early musicality. In I. Deliege \& J. Sloboda (Eds.), Musical beginnings: Origins and development of musical competence (pp. 37-55). Oxford: Oxford University Press.

Perry, N. E. (2013). Understanding classroom processes that support children's selfregulation of learning. The British Journal of Educational Psychology, Monograph Series II: Psychological Aspects of Education- Current Trends(10), 45-68.

Perry, N. E., \& VandeKamp, K. J. (2000). Creating classroom contexts that support young children's development of self-regulated learning. International Journal of Educational Research, 33(7), 821-843.

Pintrich, P. R. (2000). The role of goal orientation in self-regulated learning. In M. Boekaerts, P. Pintrich, \& M. Zeidner (Eds.), Handbook of self-regulation (pp. 451502). San Diego, CA: Academic.

Pintrich, P. R., \& Zusho, A. (2002). The development of academic self-regulation: The role of cognitive and motivational factors. In A. Wigfield \& J. Eccles (Eds.), Development of achievement motivation (pp. 249-284). San Diego, CA: Academic Press.

Pound, L. (2010). Playing music. In J. Moyles (Ed.), The excellence of play (pp. 139-153). Maidenhead: Open University Press.

Pressley, M., \& Gaskins, I. W. (2006). Metacognitively competent reading comprehension is constructively responsive reading: how can such reading be developed in students? Metacognition and Learning, 1(1), 99-113. doi: 10.1007/s11409-006-7263-7 
Puustinen, M. (1998). Help-seeking behaviour in a problem-solving situation: Development of self-regulation. European Journal of Psychology of Education, 13(2), 271-282.

Rodríguez, C., \& Palacios, P. (2007). Do private gestures have a self-regulatory function? A case study. Infant Behaviour and Development, 30(2), 180-194.

doi:10.1016/j.infbeh.2007.02.010

Roebers, C. M., Schmid, C., \& Roderer, T. (2009). Metacognitive monitoring and control processes involved in primary school children's test performance. British Journal of Educational Psychology, 79(4), 749-767.

Rothbart, M. K., Sheese, B. E., Rueda, M. R., \& Posner, M. I. (2011). Developing mechanisms of self-regulation in early life. Emotion review, 3(2), 207-213.

Saarikallio, S. (2009). Emotional self-regulation through music in 3-8-year-old children. In J.Louhivuori, T. Eerola, T.Himberg, S.Saarikallio, \& P.S. Eerola (Eds.), Proceedings of the 7th Triennial Conference of European Society for the Cognitive Sciences of Music (ESCOM). Jyväskylä, Finland: Jyväskylä University.

Schweinhart, L. J., \& Weikart, D. P. (1998). Why curriculum matters in early childhood education. Educational Leadership, 55(6), 57-60.

Shamir, A., Mevarech, Z. R., \& Gida, C. (2009). The assessment of meta-cognition in different contexts: individualized vs. peer assisted learning. Metacognition and Learning, 4(1), 47-61.

Smidt, S. (2011). Playing to learn. The role of play in the early years. London: Routledge.

Tarnowski, S. M. (1999). Musical play and young children: A music teacher can enhance a child's learning and development by encouraging musical play activities. Music Educators Journal, 86(1), 26-29. doi: 10.2307/3399573 
Thorpe, K. J., \& Satterly, D. J. H. (1990). The Development and Inter-relationship of Metacognitive Components among Primary School Children. Educational Psychology, 10(1), 5-21. doi: 10.1080/0144341900100102

Trehub, S. E., Ghazban, N., \& Corbeil, M. (2015). Musical affect regulation in infancy. Annals of the New York Academy of Sciences, 1337(1), 186-192. doi:10.1111/nyas.12622

Trevarthen, C. (2000). Musicality and the intrinsic motive pulse: evidence from human psychobiology and infant communication. Musicae Scientiae, 3(1), 155-215. doi: $10.1177 / 10298649000030 S 109$

Trevarthen, C. (2012). Communicative musicality: The human impulse to create and share music. In D. Hargreaves, D. Miell, \& R. MacDonald (Eds.), Musical imaginations. Multidisciplinary perspectives on creativity, performance and perception (pp. 259284). New York: Oxford University Press.

Vallotton, C. D. (2008). Signs of emotion: What can preverbal children "say" about internal states? Infant Mental Health Journal, 29(3), 234-258. doi: 10.1002/imhj.20175

Van der Stel, M., \& Veenman, M. V. (2010). Development of metacognitive skilfulness: A longitudinal study. Learning and Individual Differences, 20(3), 220-224. doi:10.1016/j.lindif.2009.11.005

Van der Stel, M., \& Veenman, M. V. (2014). Metacognitive skills and intellectual ability of young adolescents: A longitudinal study from a developmental perspective. European Journal of Psychology of Education, 29(1), 117-137. doi:10.1007/s10212013-0190-5

Van der Stel, M., Veenman, M. V., Deelen, K., \& Haenen, J. (2010). The increasing role of metacognitive skills in math: a cross-sectional study from a developmental 
perspective. ZDM Mathematics Education, 42(2), 219-229. doi: 10.1007/s11858009-0224-2

Veenman, M. V. J. (2015). Metacognition. In P.Afflerbach (Ed)., Handbook of Individual Differences in Reading: Reader, Text, and Context (pp. 26-40). London: Routledge.

Veenman, M. V., \& Spaans, M. A. (2005). Relation between intellectual and metacognitive skills: Age and task differences. Learning and Individual Differences, 15(2), 159-176.

Veenman, M. V., Van Hout-Wolters, B. H., \& Afflerbach, P. (2006). Metacognition and learning: Conceptual and methodological considerations. Metacognition and Learning, 1(1), 3-14. doi: 10.1007/s11409-006-6893-0

Veenman, M. V. J., Wilhelm, P., \& Beishuizen, J. J. (2004). The relation between intellectual and metacognitive skills from a developmental perspective. Learning and Instruction, 14, 89-109. doi: 10.1016/j.learninstruc.2003.10.004

Whitebread, D., Almeqdad, Q., Bryce, D., Demetriou, D., Grau, V., \& Sangster, C. (2010). Metacognition in Young Children: Current Methodological and Theoretical Developments. In A. Efklides \& P. Misailidi (Eds.), Trends and Prospects in Metacognition Research (pp. 233-258). New York: Springer.

Whitebread, D., Bingham, S., Grau, V., Pino Pasternak, D., \& Sangster, C. (2007). Development of metacognition and self-regulated learning in young children: Role of collaborative and peer-assisted learning. Journal of Cognitive Education and Psychology, 6(3), 433-455. doi: 10.1891/194589507787382043

Whitebread, D., \& Cárdenas, V. G. (2012). Self-regulated learning and conceptual development in young children: the development of biological understanding. In A. Zohar, \& Y.J. Dori (Eds.), Metacognition in Science Education: Trends in Current Research, (pp. 101-132). Springer. 
Whitebread, D., Coltman, P., Pasternak, D. P., Sangster, C., Grau, V., Bingham, S., Almeqdad, Q., Demetriou, D. (2009). The development of two observational tools for assessing metacognition and self-regulated learning in young children. Metacognition and Learning, 4(1), 63-85. doi: 10.1007/s11409-008-9033-1

Williams, K. E., Barrett, M. S., Welch, G. F., Abad, V., \& Broughton, M. (2015). Associations between early shared music activities in the home and later child outcomes: Findings from the Longitudinal Study of Australian Children. Early Childhood Research Quarterly, 31, 113-124. doi: 10.1016/j.ecresq.2015.01.004

Winsler, A., Ducenne, L., \& Koury, A. (2011). Singing one's way to self-regulation: The role of early music and movement curricula and private speech. Early Education and Development, 22(2), 274-304. doi: 10.1080/10409280903585739

Young, S. (2003). Time-space structuring in spontaneous play on educational percussion instruments among three-and four-year-olds. British Journal of Music Education, 20(01), 45-59. doi: 10.1017/S0265051702005284

Young, S. (2004). The interpersonal dimension: a potential source of musical creativity for young children? Musicae Scientiae, 7(1), 175-191.doi:10.1177/10298649040070S109

Young, S. (2005). Adults and young children communicating musically. In D. Hargreaves, D. Miell, \& D. MacDonald (Eds.), Musical Communication (pp. 281-299). Oxford: Oxford University Press.

Zachariou, A., \& Whitebread, D. (2015). Musical play and self-regulation: does musical play allow for the emergence of self-regulatory behaviours? International Journal of Play, 4(2), 116-135. https://doi.org/10.1080/21594937.2015.1060572.

Zachariou, A., \& Whitebread, D. (2017). A New Context Affording for Regulation: The Case of Musical Play. International Journal of Educational Psychology, 6(3), 212-249. https://doi.org/10.17583/ijep.2017.2959. 
Zeidner, M., Boekaerts, M., \& Pintrich, P. (2000). Self-regulation. Directions and challenges for future research. In M. Boekaerts, P. Pintrich, \& M. Zeidner (Eds.), Handbook of self-regulation (pp. 749-768). San Diego, CA: Academic Press. 


\section{Tables}

Table 1. Mean rates and standard deviations of areas of regulatory behaviour during musical play (per age-group).

\section{6-year-olds}

8-year-olds

\begin{tabular}{lcccc}
\hline Area of regulatory behaviour & $M$ & $S D$ & $M$ & $S D$ \\
\hline Metacognitive regulation & 4.48 & 1.24 & 5.91 & 1.86 \\
Emotional/motivational & 2.15 & 0.53 & 2.77 & 0.55 \\
regulation & & & & \\
Metacognitive knowledge & 0.16 & 0.09 & 0.20 & 0.13 \\
& & & & \\
\hline
\end{tabular}


Table 2. Mean rates and standard deviations of specific regulatory behaviours (per agegroup).

\section{6-year-olds}

\section{8-years-old}

\begin{tabular}{|c|c|c|c|c|}
\hline Regulatory behaviour & $M$ & $S D$ & $M$ & $S D$ \\
\hline $\begin{array}{l}\text { Metacognitive knowledge of } \\
\text { persons }\end{array}$ & 0.07 & 0.05 & 0.08 & 0.06 \\
\hline $\begin{array}{l}\text { Metacognitive knowledge of } \\
\text { tasks }\end{array}$ & 0.04 & 0.04 & 0.04 & 0.03 \\
\hline $\begin{array}{l}\text { Metacognitive knowledge of } \\
\text { strategies }\end{array}$ & 0.05 & 0.04 & 0.08 & 0.06 \\
\hline Planning & 0.95 & 0.24 & 1.29 & 0.44 \\
\hline Monitoring & 2.37 & 0.64 & 3.26 & 0.95 \\
\hline Control & 1.00 & 0.45 & 1.14 & 0.51 \\
\hline Evaluation & 0.15 & 0.11 & 0.22 & 0.11 \\
\hline $\begin{array}{l}\text { Emotional/motivational } \\
\text { monitoring }\end{array}$ & 1.90 & 0.48 & 2.50 & 0.45 \\
\hline $\begin{array}{l}\text { Emotional/motivational } \\
\text { control }\end{array}$ & 0.25 & 0.14 & 0.28 & 0.14 \\
\hline
\end{tabular}


Table 3. Mean rates and standard deviations per social intentionality of regulatory behaviour (per age-group).

\section{6-year-olds}

\section{8-year-olds}

\begin{tabular}{lcccc}
\hline Social intentionality & $M$ & $S D$ & $M$ & $S D$ \\
\hline Socially-shared regulation & 3.29 & 1.16 & 4.48 & 1.37 \\
Self-regulation & 2.22 & 0.59 & 2.50 & 0.76 \\
Co-regulation & 1.35 & 0.64 & 1.88 & 0.93 \\
& & & & \\
\hline
\end{tabular}


Figures

\begin{tabular}{|l|l|}
\hline \multicolumn{2}{|c|}{ Self-regulation } \\
\hline Areas of regulatory behaviour & Specific regulatory behaviours \\
\hline Metacognitive knowledge & Metacognitive knowledge of person \\
\cline { 2 - 2 } & Metacognitive knowledge of task \\
\cline { 2 - 2 } & Metacognitive knowledge of strategies \\
\hline Metacognitive regulation & Planning \\
\cline { 2 - 2 } & Monitoring \\
\cline { 2 - 2 } & Control \\
\cline { 2 - 2 } & Evaluation \\
\hline Emotional/motivational regulation & Emotional/motivational monitoring \\
\cline { 2 - 2 } & Emotional/ motivational control \\
\hline
\end{tabular}

Fig. 1 Self-regulation's elements: self-regulatory areas and specific self-regulatory behaviours (Whitebread et al., 2009) 


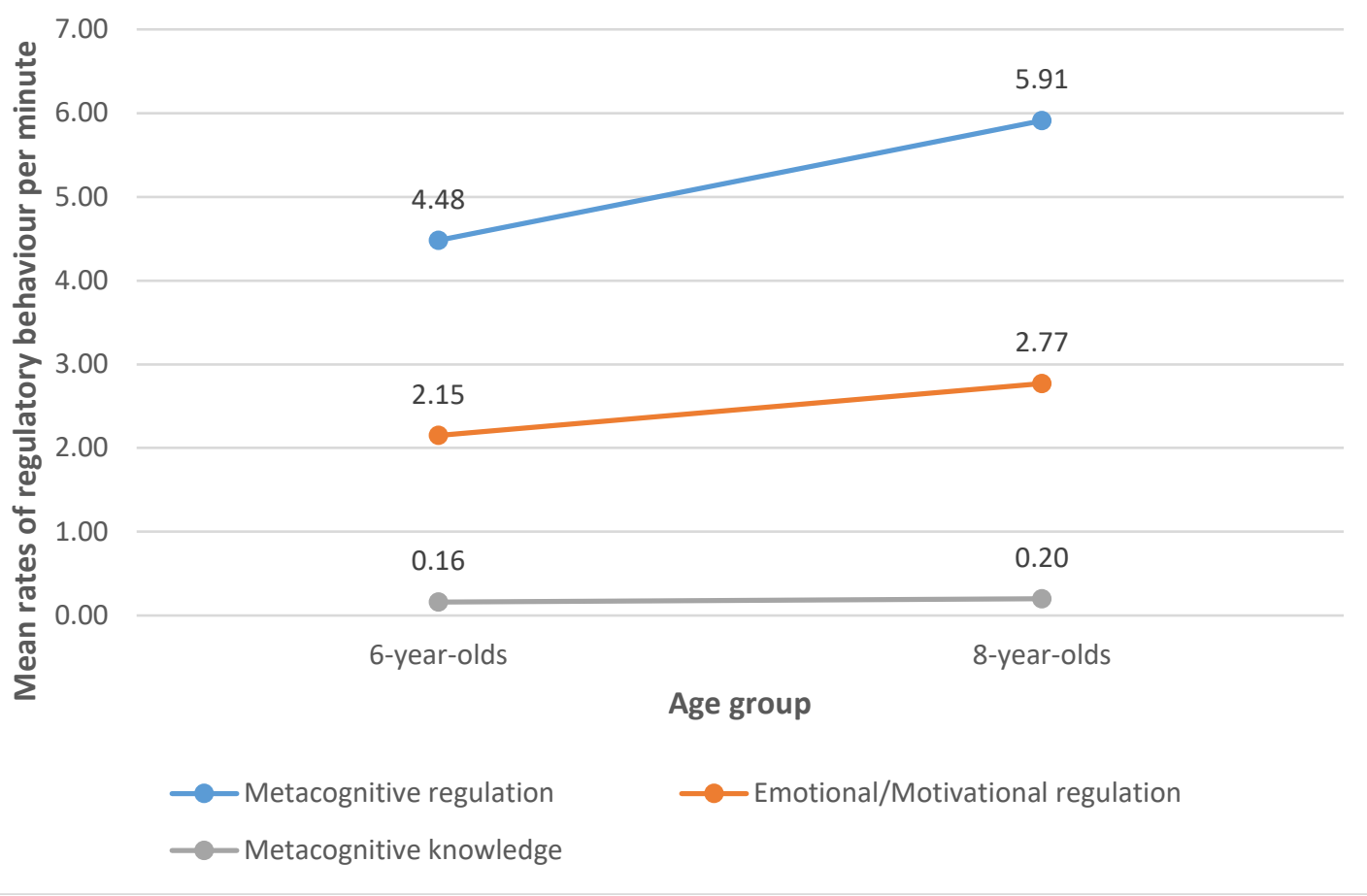

Fig. 2 Interaction graph showing the Age group x Area of regulation interaction 


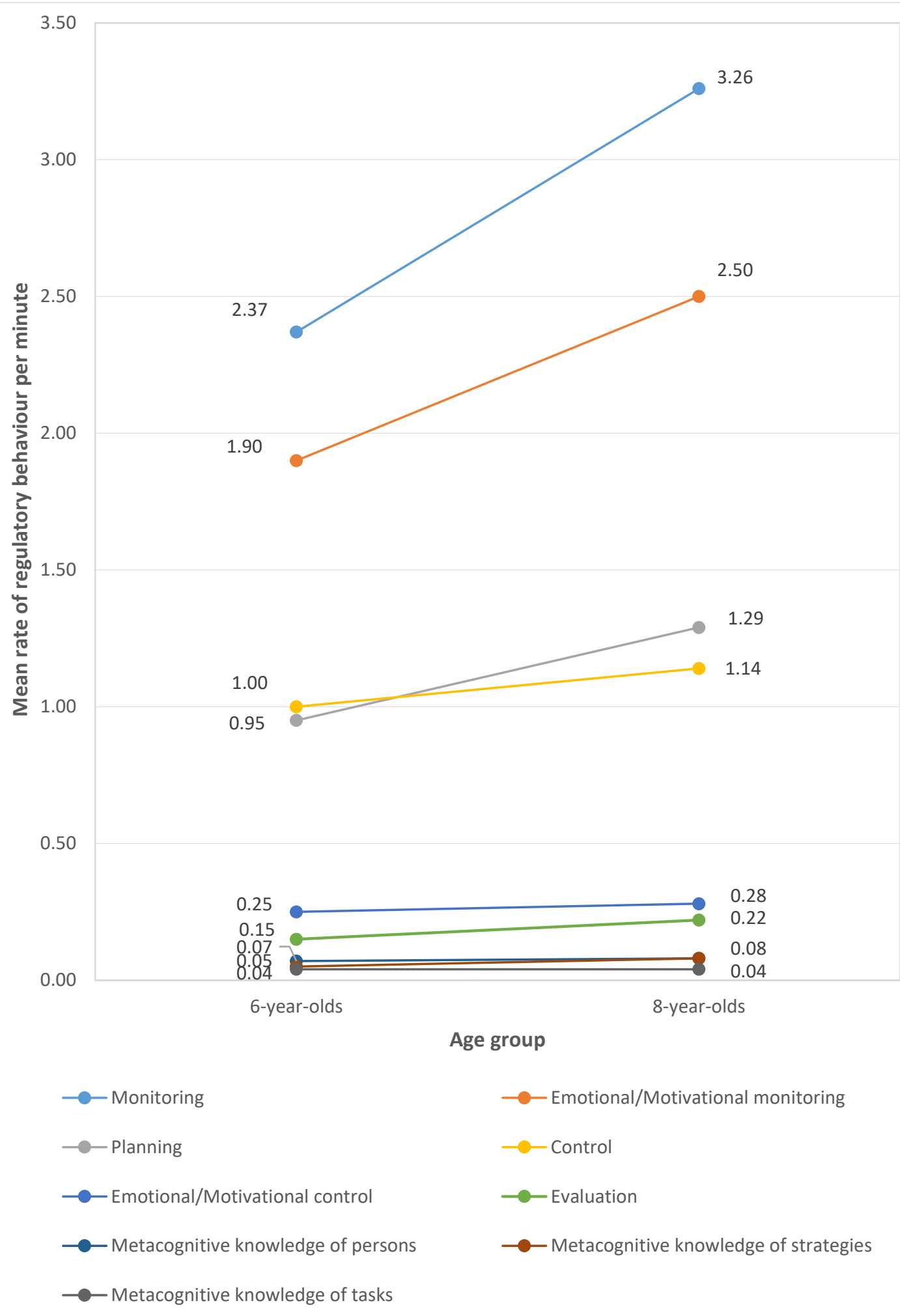

Fig. 3 Interaction graph showing the Age group x Specific regulatory behaviour interaction 


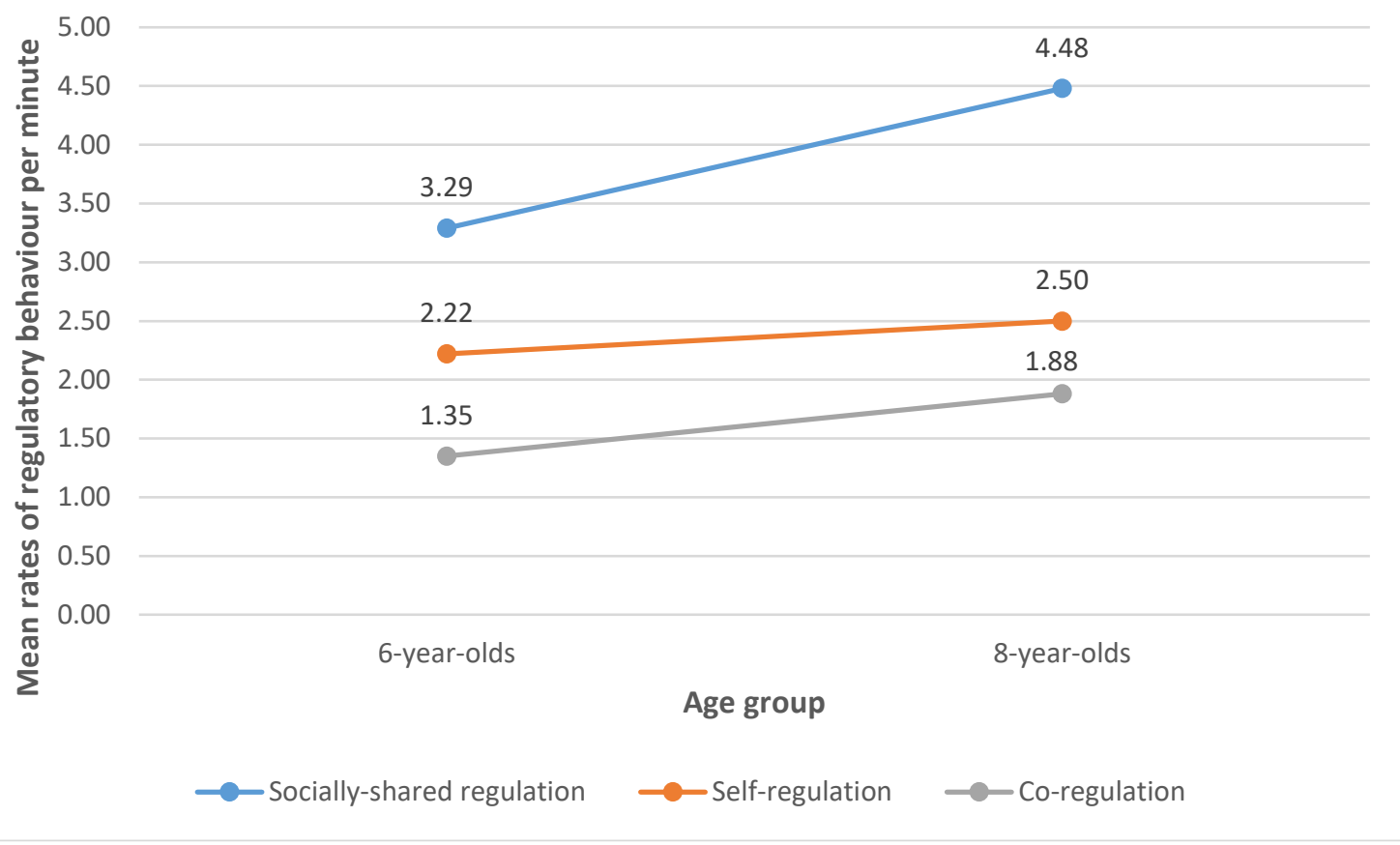

Fig. 4 Interaction graph showing the Age group $x$ Social intentionality of regulation interaction 


\section{Appendix A}

Examples of different types of regulatory behaviour observed during musical play

\begin{tabular}{|c|c|}
\hline $\begin{array}{l}\text { General areas and } \\
\text { specific types of regulation }\end{array}$ & Examples \\
\hline \multicolumn{2}{|l|}{ Metacognitive knowledge } \\
\hline Knowledge of persons & $\begin{array}{l}\text { I don't want to sing; I am not good at it } \\
\text { Do you know why (I am doing this so well)? I have been practicing! }\end{array}$ \\
\hline Knowledge of tasks & $\begin{array}{l}\text { Explains what the task lacks in comparison to other ideas. } \\
\text { [to peer] Ah, it is too difficult! } \\
\text { Identifies similarities to hand-clapping games they already know } \\
\text { [Hand-clapping] }\end{array}$ \\
\hline Knowledge of strategies & $\begin{array}{l}\text { Explains to the rest of the group the game. You will be closing the } \\
\text { circle when I enter the circle and you will be singing this [Circle } \\
\text { games] }\end{array}$ \\
\hline \multicolumn{2}{|l|}{ Metacognitive regulation } \\
\hline Planning & $\begin{array}{l}\text { Child tries to get the team ready and at the correct position before the } \\
\text { start of play. } \\
\text { Directs who plays what and when. } \\
\text { Gets his peer's hands ready in the correct position before they start } \\
\text { playing [Hand-clapping]. }\end{array}$ \\
\hline Monitoring & $\begin{array}{l}\text { Checking around their peers to make sure they are doing it correctly. } \\
\text { Commenting on the song. } \\
\text { Monitoring their play while on task. }\end{array}$ \\
\hline Control & $\begin{array}{l}\text { Guides another child by demonstration of how the instrument should } \\
\text { be used } \\
\text { Nods to a peer to point out it is her turn to move [Movement play]. } \\
\text { "One, two, three"-implementing a known strategy to a new situation. }\end{array}$ \\
\hline Evaluation & $\begin{array}{l}\text { We've made a song! It's perfect! [Singing play] } \\
\text { This dance (we are creating) fits really well with the song. [Movement } \\
\text { play] }\end{array}$ \\
\hline $\begin{array}{l}\text { Emotional and } \\
\text { motivational regulation } \\
\text { Emotional/motivational } \\
\text { monitoring }\end{array}$ & $\begin{array}{l}\text { I don't want to sing. [Singing play] } \\
\text { Smiling, laughing, pulling a long face. Looking excited. }\end{array}$ \\
\hline $\begin{array}{l}\text { Emotional/motivational } \\
\text { control. }\end{array}$ & $\begin{array}{l}\text { Nods her head encouragingly to make a peer dance [Circle games]. } \\
\text { His peer is not paying attention to him but he still persists trying to get } \\
\text { his hands in the correct position for the start of the game [hand- } \\
\text { clapping games]. }\end{array}$ \\
\hline
\end{tabular}

Reproduced from 'A New Context Affording for Regulation: The Case of Musical Play', by A. Zachariou and D. Whitebread, 2017, International Journal of Educational Psychology, 6(3), 212-249. Copyright 2017 by A. Zachariou and D. Whitebread. Reprinted courtesy of the Copyright Holder under a Creative Commons Attribution License CC-BY (https://creativecommons.org/licenses/by/4.0/ ) 


\section{Appendix B}

Examples of regulatory behaviours of different social intentionality

\begin{tabular}{ll}
\hline Social Intentionality & Example \\
\hline Self-regulation & $\begin{array}{l}\text { Child realises that he made a mistake and played his instrument at } \\
\text { the wrong moment. Immediately self-corrects and stops. }\end{array}$ \\
& $\begin{array}{l}\text { Following moving on the musical piece in the way he had } \\
\text { suggested, stops and announces 'I am bored of this one (this pattern } \\
\text { of moves)' } \\
\text { Closely monitoring another child's effort and nodding her head in } \\
\text { approval. } \\
\text { One of the group members misbehaves. Another child raises the } \\
\text { tone of her voice and touches him on the knee, saying in a slightly } \\
\text { annoyed tone: 'Hey, come on' (Behave!). } \\
\text { All children in the group are discussing their ideas for the lyrics of } \\
\text { their song together, with everyone suggesting an idea. }\end{array}$ \\
$\begin{array}{l}\text { Socially-shared } \\
\text { regulation }\end{array}$ &
\end{tabular}

Reproduced from 'A New Context Affording for Regulation: The Case of Musical Play', by A. Zachariou and D. Whitebread, 2017, International Journal of Educational Psychology, 6(3), 212-249. Copyright 2017 by A. Zachariou and D. Whitebread. Reprinted courtesy of the Copyright Holder under a Creative Commons Attribution License CC-BY (https://creativecommons.org/licenses/by/4.0/ ) 